\title{
Safety of sputum induction in chronic obstructive pulmonary disease
}

\author{
P.H. Rytilä, A.E. Lindqvist, L.A. Laitinen
}

Safety of sputum induction in chronic obstructive pulmonary disease. P.H. Rytilä, A.E. Lindqvist, L.A. Laitinen. (C) ERS Journals Ltd 2000.

ABSTRACT: The aim of the present study was to evaluate the safety of sputum induction in patients with varying severity of chronic obstructive pulmonary disease.

The subjects were 28 smokers with baseline forced expiratory volume in one second (FEV1) of (mean and range) $1.8(0.8-2.9) \mathrm{L}$ that is $53(28-69) \%$ of the predicted and reversibility of $2.5(-7.4-9.9) \%$. Sputum was induced after premedication with $200 \mu \mathrm{g}$ salbutamol at increasing concentrations $(0.9,3,4$, and $5 \%)$ of hypertonic saline nebulized by an ultrasonic nebulizer.

The procedure was well tolerated, and none of the patients reported major sideeffects. However, the mean change from prebronchodilator FEV1 during induction was $-8.5(-23-11) \%, p=0.001$, and from postbronchodilator FEV1 $-10.7(-25-5) \%$, $p<0.0001$. Three $(11 \%)$ of the patients had a fall in FEV1 from the prebronchodilator baseline of $>20 \%$, and a further $10(36 \%)$ had a fall of $10-20 \%$. Patients with greater reversibility in airway obstruction seemed to get the best benefit from the bronchodilator pretreatment, since there was an inverse relationship between reversibility in FEV1 and fall in FEV1 during induction $(r=-0.4, p=0.03)$.

It is concluded that sputum induction by hypertonic saline inhalation can cause meaningful bronchoconstriction in patients with chronic obstructive pulmonary disease, despite pretreatment with an inhaled $\beta_{2}$-agonist. The results highlight the importance of monitoring spirometry during sputum induction to detect bronchoconstriction.

Eur Respir J 2000; 15: 1116-1119.
Dept of Medicine, Division of Pulmonary Medicine, Helsinki University Central Hospital, Helsinki, Finland.

Correspondence: P. Rytilä, Dept of Medicine, Research Unit of Pulmonary Medicine, Helsinki University Central Hospital, PBOX 340, FIN-00029 HYKS, Helsinki, Finland. Fax: 358947172691 .

Keywords: Chronic obstructive pulmonary disease induced sputum safety

Received: October 61999

Accepted after revision March 82000

The study was supported by Astra Charnwood, UK and P. Rytilä was supported by a grant from the Ida Montin Foundation, Finland.
Sputum induction by inhalation of hypertonic saline has been used as a direct and relatively noninvasive method to investigate airway inflammation. It has been applied in patients with asthma and chronic obstructive pulmonary disease (COPD) [1-4]. Sputum-induction methodology may offer important benefits in diagnosing patients with airflow obstruction and in comparing treatment strategies.

Although no standardized method for the induction of sputum has been agreed upon, recently a consensus on the use of sputum induction in asthma has appeared [5]. The challenge procedure should be performed in a standardized manner, because hypertonic saline can cause asthmatics to suffer from airway constriction. This procedure includes spirometry before and during the induction as well as pretreatment with a short-acting $\beta_{2}$-agonist.

Some studies assess the safety of sputum induction in patients with asthma [6-8], but information on patients with COPD is scarce $[3,4]$. The aim of the present study was to evaluate the safety and success of sputum induction in patients with varying severity of COPD [9].

\section{Materials and methods}

\section{Subjects}

The authors studied 28 patients with at least a 2-yr clinical diagnosis of symptomatic COPD [10] and a smoking history of 20-103 pack-yrs (table 1). Two (7\%) of them were exsmokers, all others were current smokers. Patients had to fulfil the following criteria: 1) prebronchodilator forced expiratory volume in one second (FEV1) of $<70 \%$ of the predicted [11]; 2 ) $<10 \%$ reversibility from prebronchodilator FEV1 to short-acting $\beta_{2}$-agonist (200 $\mu \mathrm{g}$ of salbutamol). Patients treated for disease exacerbation or needing antibiotics for respiratory-tract infections during 6 weeks prior to the study were excluded.

FEV1 (mean and range) was $1.8(0.8-2.9) \mathrm{L}$, that is 53 $(28-69) \%$ pred and FEV1/forced vital capacity was 52 (33-67)\%. Reversibility to $200 \mu \mathrm{g}$ of inhaled salbutamol was 2.5 (-7.4-9.9)\% (table 1). Four (14\%) patients used inhaled steroids (beclomethasone or budenoside, mean dose $900 \mu \mathrm{g} \cdot \mathrm{day}^{-1}$, range $800-1200 \mu \mathrm{g} \cdot \mathrm{day}^{-1}$ ) and two $(7 \%)$ oral theophylline. None had regular oral steroid treatment. Five $(18 \%)$ received short-acting $\beta_{2}$-agonists and three $(11 \%)$ anticholinergics as a rescue medication. Only one (4\%) showed clinical evidence of allergy or atopy.

The study was approved by the ethics committee of Helsinki University Central Hospital (Helsinki, Finland), and all subjects gave their informed consent.

\section{Study design}

Two weeks before sputum induction, spirometry was performed and reversibility in FEV1 was assessed (Spirotrac III; Vitalograph, Maids Moreton, UK). For FEV1, the 
Table 1. - Characteristics of subjects

\begin{tabular}{lc}
\hline $\mathrm{n}$ & 28 \\
Age & $60(51-68)$ \\
Male & $19(68 \%)$ \\
Smoking pack-yrs & $52(20-103)$ \\
Inhaled steroids & $4(14 \%)$ \\
Symptom score* & $6.4(3.3-11)$ \\
$\Delta$ PEF \% & $8.9(1.9-39)$ \\
Baseline FEV1 L & $1.8(0.8-2.9)$ \\
Baseline FEV1 \% pred & $53(28-69)$ \\
Baseline FVC L & $3.5(1.9-5.3)$ \\
Baseline FEV1/FVC \% & $52(33-67)$ \\
Reversibility in FEV1\% & $2.5(-7.4-9.9)$ \\
\hline
\end{tabular}

Data expressed as mean and range or number and percentage. FEV1: forced expiratory volume in one second; FVC: forced vital capacity. *: average sum of three symptoms (cough, sputum-production, shortness of breath) per day, see Methods section. : average diural peak expiratory flow (PEF) variation during 1-week follow-up, see Methods section.

greatest accepted difference between the two highest values among three or more technically acceptable determinations was 4\% [12]. During 1-2 weeks time before sputum induction, patients measured their peak expiratory flow (Mini Wright peak flow meter; Clement Clarke Int., London, UK) every morning and evening. They also recorded daily symptoms (cough, sputum-production, shortness of breath) on a scale ranging 0-4 (table 1). Patients were allowed to continue their usual medication for COPD, with the exception of long-acting bronchodilator therapy, which was not allowed for the 2 weeks prior to sputum induction. Short-acting bronchodilators were not allowed $4 \mathrm{~h}$ prior to induction.

\section{Sputum induction}

Sputum was induced by the method first described by Pizzichini et al. [9]. Before induction, spirometry was performed, after which $200 \mu \mathrm{g}$ of salbutamol was given by metered dose inhaler. The inhalation technique was checked and medication was given under supervision of a trained nurse. Ten minutes later postbronchodilator spirometry was obtained. If the postbronchodilator FEV1 was $<1 \mathrm{~L}$, only $0.9 \%$ hypertonic saline was used, and FEV1 was checked every $3 \mathrm{~min}$. If the postbronchodilator FEV 1 was $>1 \mathrm{~L}$, induction was started with $3 \%$ hypertonic saline, and FEV1 was obtained every $7 \mathrm{~min}$. The inhalation was stopped if FEV1 dropped by $>20 \%$, if bothersome symptoms occurred, or when the sputum sample was adequate. The inhalation was followed by postinduction spirometry. Duration of inhalation was calculated as time required to reach the end of inhalation or to decrease FEV1 by $>20 \%$. The hypertonic saline solution was nebulized with an ultrasonic nebulizer (Ultra-neb 2000; DeVilbiss Health Care Inc., Somerset, PA, USA); (output $2.5 \mathrm{~mL} \cdot \mathrm{min}^{-1}$, particle size $\left.4.5 \mu \mathrm{m}\right)$.

\section{Sputum processing}

The authors used the method of sputum examination of Pizzichini et al. [13]. Briefly, all sputum macroscopically free of salivary contamination was selected and treated with dithiothreitol (Sputolysin 10\%; Calbiochem Corp., San Diego, CA, USA) and phosphate-buffered saline.
The suspension was centrifuged, and the supernatant was aspirated and stored in microfuge tubes at $-20^{\circ} \mathrm{C}$ for later assay. The cell pellet was resuspended, and the absolute number of cells per milligram of processed sputum was calculated. Coded cytospins were prepared and stained by May-Grünwald Giemsa stain and by toluidine blue in order to obtain a cell differential count. The sputum sample was considered adequate if it had $<80 \%$ squamous epithelial cell contamination from saliva. The results are expressed as percentage of individual cells of the total nonsquamous cell count.

From sputum supernatant the concentrations $\left(\mu \mathrm{g} \cdot \mathrm{L}^{-1}\right)$ of eosinophil activation marker eosinophil cationic protein (ECP), and the neutrophil activation marker, myeloperoxidase (MPO), were measured using commercially available immunoassay kits (Pharmacia \& Upjohn Diagnostics, Uppsala, Sweden).

\section{Data analysis}

The authors calculated the change in FEV1 from the prebronchodilator and from the postbronchodilator baseline. Data are expressed as mean and range. Comparisons of different patients groups were analysed by the MannWhitney U-test and Chi-squared test, when appropriate. Correlation was analysed by Spearman's rank correlation test. Wilcoxon's test for paired data was used to analyse changes in the same patient. Two-tailed p-values $<0.05$ were considered significant.

\section{Results}

The sputum induction procedure was well tolerated, and no patients reported major side-effects. An adequate sputum sample was obtained from 27 (96\%) patients. The mean change from the prebronchodilator FEV1 during induction was $-162(-541-205) \mathrm{mL}$ that is $-8.5(-23-11) \%$, $\mathrm{p}=0.001$, and from the postbronchodilator FEV1 -202 ($625-95) \mathrm{mL}$ that is $-10.7(-25-5) \%, \mathrm{p}<0.0001$ (table 2 , fig. $1)$. Three $(11 \%)$ of the subjects had a fall in FEV1 from the prebronchodilator baseline value of $>20 \%$, and a further $10(36 \%)$ had a fall of $10-20 \%$. All patients with a fall in FEV 1 of $\geq 20 \%$ were followed carefully and treated with inhaled salbutamol.

Table 2. - Sputum-induction data

Patients $\mathrm{n}=28$

\begin{tabular}{lc}
\hline Prebronchodilator & \\
Baseline & $-162(-541-205)$ \\
Change in FEV1 mL & $-8.5(-23-11)$ \\
$\%$ change in FEV1 & \\
Postbronchodilator & \\
Baseline & $-202(-625-95)$ \\
Change in FEV1 mL & $-10.7(-25-5)$ \\
$\%$ change in FEV1 & \\
Final saline concentration & $3(11 \%)$ \\
$0.9 \%$ & $21(75 \%)$ \\
$3 \%$ & $4(14 \%)$ \\
$4 \%$ & $0(0 \%)$ \\
$5 \%$ & $8.3(2-21)$ \\
Induction time & \\
\hline
\end{tabular}

Data expressed as mean and range or number and percentage. FEV 1: forced expiratory volume in one second. ${ }^{+}: \mathrm{p}=0.001$; $\mathrm{p}<0.0001$. 


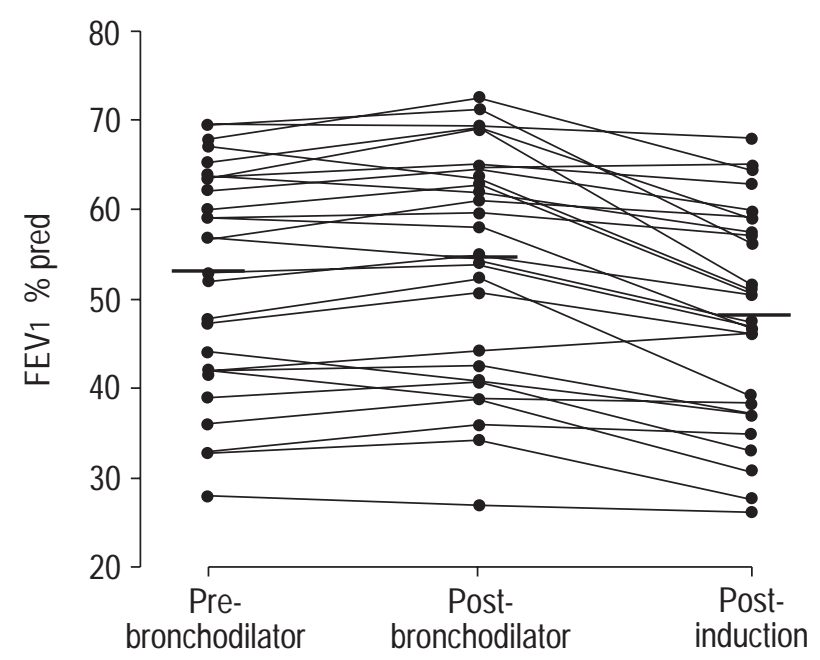

Fig. 1. - Forced expiratory volume in one second (FEV1) as measured before and after salbutamol pretreatment and after sputum induction. Prebronchodilator FEV1 increased significantly after salbutamol $(\mathrm{p}=$ 0.03 , Wilcoxon's test). During induction FEV1 fell significantly ( $\mathrm{p}=$ 0.001 from the prebronchodilator baseline, $\mathrm{p}<0.0001$ from the postbronchodilator baseline). Horizontal bars represent the mean of all samples.

Three female patients $(11 \%)$ had a postbronchodilator FEV1 of $<1$ L, $0.87(0.81-0.94)$ L, $36(34-38) \%$ pred, and sputum was induced using $0.9 \%$ saline only. The mean change in FEV1 in these patients was $-60(-118-53) \mathrm{mL}$, that is $-7.2(-15-7) \%$ from the prebronchodilator baseline, and $-120(-188-17) \mathrm{mL}$, that is $-13.7(-20-2) \%$ from the postbronchodilator baseline.

The sputum total and differential cell counts as well as ECP and MPO results are shown in table 3. A statistically significant inverse relationship existed between reversibility in FEV1 and fall in FEV1 during induction, $(r=-0.4$, $\mathrm{p}=0.03$; fig. 2). Otherwise, the authors could find no correlations among sputum markers and baseline clinical characteristics and change in FEV1 during induction. No significant differences existed in any of the parameters between females and males or between patients on inhaled steroids and steroid naive-patients.

\section{Discussion}

It was found that $11 \%$ of the patients with COPD had a fall in FEV 1 of $>20 \%$ during the induction procedure and another $36 \%$ a fall in FEV1 of $10 \%-20 \%$. The mean fall from the prebronchodilator baseline FEV1 during induction

Table 3. - Sputum inflammatory markers

\begin{tabular}{lc}
\hline Sputum total cell count $10^{3} \cdot \mathrm{mg}^{-1}$ & $1.9(0.09-15)$ \\
Eosinophils \% & $2.0(0-11)$ \\
Neutrophils \% & $62(38-89)$ \\
Lymphocytes \% & $0.4(0-4)$ \\
Macrophages \% & $36(9-62)$ \\
Bronchial epithelial cells \% & $0.10(0-4.0)$ \\
Squamous epithelial cells \% & $6.8(0-35)$ \\
Metacromatic cells \% & $0.10(0-1.0)$ \\
ECP $\mu \mathrm{g} \cdot \mathrm{L}^{-1}$ & $1218(36-4460)$ \\
MPO $\mu \mathrm{g} \cdot \mathrm{L}^{-1}$ & $12320(531-45540)$ \\
\hline
\end{tabular}

Data are expressed as mean with range in parenthesis. ECP: eosinophil cationic protein; MPO: myeloperoxidase.

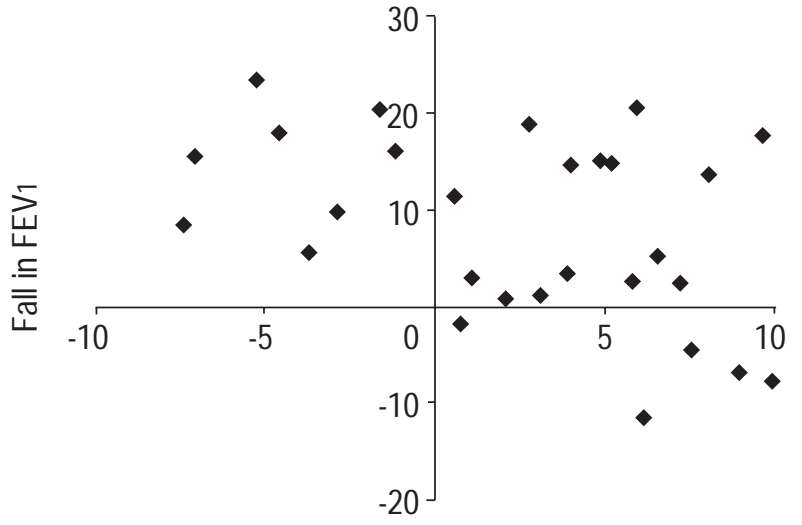

Reversibility in FEV1

Fig. 2. - Relationship between reversibility in forced expiratory volume in one second (FEV1) and fall in FEV1 from prebronchodilator baseline during sputum induction, $(\mathrm{r}=-0.4, \mathrm{p}=0.03$, Spearman rank correlation).

was $8.5 \%$, and from the postbronchodilator baseline $10.7 \%$. However, all patients tolerated the sputum-induction procedure well and failed to report any major side-effects, although airway obstruction caused by the induction procedure did occur.

Pretreatment with a bronchodilator failed to prevent a fall in FEV1, especially in patients with no or slight reversibility in FEV1 caused by pretreatment salbutamol. The fall in FEV1 during sputum induction was inversely correlated with reversibility in FEV1. This indicates that COPD patients with more reversibility in FEV1 may gain the best benefit from bronchodilator pretreatment against bronchoconstriction. Airway hyperreactivity and reversibility of airway obstruction are thought to be the characteristic features of asthma but can be seen in COPD as well. It has been shown that increased airway responsiveness in smokers is a risk factor for accelerated decline in FEV1 over time and hence for the development of COPD [14].

The original studies introducing the sputum induction method reported few side-effects and no fall in FEV1 [15, 16]. Studies concentrating upon safety aspects of sputum induction have found it safe even in patients with severe asthma [6-9] and in COPD [1-4]. Studies have proposed that sputum should not be induced in asthmatic patients with a postbronchodilator FEV1 of $<1 \mathrm{~L}$ or $60 \%$ pred [57]. An aerosol of normal saline followed by hypertonic saline has, however, been safely used in patients with severe exacerbations of asthma [9]. The current authors applied a similar approach to their patients with a postbronchodilator FEV1 of $<1 \mathrm{~L}$, and the fall in FEV1 was not significant.

It remains unclear whether the magnitude of bronchoconstriction depends on hypertonicity of the saline, the total amount inhaled, or the rate of delivery, or if it could be prevented by pretreatment with larger doses of inhaled salbutamol [17-19]. The current authors used a fairly high-output ultrasonic nebulizer (output $2.5 \mathrm{~mL} \cdot \mathrm{min}^{-1}$, particle-size $4.5 \mu \mathrm{m}$ ). The original paper on asthmatics by PIN et al. [15] used a relatively low-output ultrasonic nebulizer (output $0.9 \mathrm{~mL} \cdot \mathrm{min}^{-1}$, particle-size $5.6 \mu \mathrm{m}$ ), with which significant bronchoconstriction rarely occurred.

In conclusion, the authors have shown that sputum induction by inhalation of hypertonic saline can, in patients 
with chronic obstructive pulmonary disease, cause bronchoconstriction. Patients whose airway obstruction is more reversible seem to be better protected by bronchodilator pretreatment. The results highlight the importance of monitoring spirometry during sputum induction in order to detect bronchoconstriction.

Acknowledgements. The authors wish to thank K. Ahlskog, T. Metso, E. Repo, M. Veneranta, and E-L. Kiiskilä for technical assistance.

\section{References}

1. Maestrelli P, Calcagni PG, Saetta $\mathrm{M}$, et al. Integrin upregulation on sputum neutrophils in smokers with chronic airway obstruction. Am J Respir Crit Care Med 1996; 154: 1296-1300.

2. Keatings VM, Collina PD, Scott DM, Barnes PJ. Differences in interleukin-8 and tumour necrosis factoralpha in induced sputum from patients with chronic obstructive pulmonary disease and asthma. Am J Respir Crit Care Med 1996; 153: 530-534.

3. Bhowmilk A, Seemungal TAR, Sapsford RJ, Devalia JL, Wedzicha JA. Comparison of spontaneous and induced sputum for investigation of airway inflammation in chronic obstructive pulmonary disease. Thorax 1998; 53: 953-956.

4. Peleman RA, Rytilä PH, Kips JC, Joos GF, Pauwels RA. The cellular composition of induced sputum in chronic obstructive pulmonary disease. Eur Respir J 1999; 13: 839-843.

5. Kips JC, Fahy JV, Hargreave FE, Ind PW, in't Veen JCCM. Methods for sputum induction an analysis of induced sputum: a method for assessing airway inflammation in asthma. Eur Respir J 1998; 11: 9s-12s.

6. Wong HH, Fahy JV. Safety of one method of sputum induction in asthmatic subjects. Am J Respir Crit Care Med 1997; 156: 299-303.

7. de la Fuente PT, Romagnoli M, Godard P, Bousquet J, Chanez P. Safety of inducing sputum in patients with asthma of varying severity. Am J Respir Crit Care Med 1998; 157: 1127-1130.

8. Grootendorst DC, van den Bos J-W, Romeijn JJ, et al. Induced sputum in adolescents with severe stable asthma.
Safety and the relationship of cell counts and eosinophilic cationic protein to clinical severity. Eur Respir J 1999; 13: 647-653.

9. Pizzichini MMM, Pizzichini E, Clelland L, et al. Sputum in severe exacerbations of asthma: kinetics of inflammatory indices after prednisone treatment. Am J Respir Crit Care Med 1997; 155: 1501-1508.

10. The American Thoracic Society. Standards for the diagnosis and care of patients with chronic obstructive pulmonary disease (COPD) and asthma. Am J Respir Crit Care Med 1995; 152: S77-S120.

11. Viljanen A. Reference values for spirometric, pulmonary diffusing capacity and body plethysmographic studies. Scan J Clin Lab Invest 1982; 42: 1-50.

12. Quanjer PhH, Tammeling GJ, Cotes JE, Pedersen OF, Peslin R, Yernault J-C. Lung volumes and forced ventilatory flows. Report Working Party Standardization of Lung Function Tests, European Community for Steel and Coal. Official Statement of the European Respiratory Society. Eur Respir J 1993; 6: Suppl. 16, 5-40.

13. Pizzichini E, Pizzichini MMM, Efthimiadis A, et al. Indices of airway inflammation in induced sputum: reproducibility and validity of cell and fluid phase measurements. Am J Respir Crit Care Med 1996; 154: 308-317.

14. Rijcken B, Schouten JP, Xu X, Rosner B, Weiss ST. Airway hyperresponsiveness to histamine associated with accelerated decline in FEV1. Am J Respir Crit Care Med 1995; 151: 1377-1382.

15. Pin I, Gibson PG, Kolendowicz R, et al. Use of induced sputum cell count to investigate airway inflammation in asthma. Thorax 1992; 47: 25-29.

16. Fahy JV, Liu J, Wong H, Boushey HA. Cellular and biochemical analysis of induced sputum from asthmatic and from healthy subjects. Am Rev Respir Dis 1993; 147: 1126-1131.

17. Popov TA, Pizzichini MMM, Pizzichini E, et al. Some technical factors influencing the induction of sputum for cell analysis. Eur Respir J 1995; 8: 559-565.

18. Bacci E, Cianchetti S, Paggiaro PL, et al. Comparison between hypertonic and isotonic saline-induced sputum in the evaluation of airway inflammation in subjects with moderate asthma. Clin Exp Allergy 1996; 26: 1395-1400.

19. Pavord ID. Sputum induction to assess airway inflammation: is it an inflammatory stimulus? Thorax 1998; 53: $79-80$. 